\title{
Is Autonomic Function Impaired in Patients with Pseudoexfoliation Syndrome?
}

\author{
Ayhan Coșgun' (1), Alper Güneș² (1) \\ 'Department of Cardiology, Sincan State Hospital, Ankara, Turkey \\ 2Department of Ophthalmology, Tokat Gaziosmanpașa University, Faculty of Medicine, Tokat, Turkey
}

ORCID iDs of the authors: A.C. 0000-000I-5I47-I6IX; A.G. 0000-000I-92I3-8805.

Cite this article as: Coșgun A, Güneș A. Is Autonomic Function Impaired in Patients with Pseudoexfoliation Syndrome? Cyprus J Med Sci 2020; 5(3): 200-4.

\section{BACKGROUND/AIMS}

Pseudoexfoliative syndrome is an aging disease that progresses primarily with the accumulation of fibrillary materials in the eye and in some organs other than the eye, particularly in the heart. Accumulation of this substance in the heart is closely related to morbidity and mortality. This study aimed to evaluate the heart rate recovery index (HRR-I), which is a predictor of autonomic dysfunction.

\section{MATERIAL and METHODS}

A total of 253 patients diagnosed with PEX in the ophthalmology outpatient clinic between March 2018 and May 2019 were included in the study. The control group consisted of 238 participants who were diagnosed as non-PEX and had no disease. After routine physical and blood examinations, both groups underwent routine electrocardiograms, transthoracic echocardiograms, and treadmill exercise test (TET). Heart rates of the study and control groups were recorded at the beginning, peak exercise, first, second, and third recovery levels of TET. Heart rate recovery index (HRR-I) values of the first, second, and third minutes were subtracted from the peak level HR values and compared.

\section{RESULTS}

In the study group, first-minute HRR-I value ( $20.93 \pm 5.93 \mathrm{~ms}$ vs. $32.1 \mathrm{I} \pm 5.43 \mathrm{~ms}, \mathrm{t}=21.74$ and $\mathrm{p}<0.0 \mathrm{l})$, second-minute HRR-I value ( $38.83 \pm 6.99 \mathrm{~ms}$ vs. $51.65 \pm 7.12 \mathrm{~ms}, t=20.12$ and $p<0.01)$, and third-minute HRR-I value $(62.76 \pm 9.56 \mathrm{~ms}$ vs. $77.21 \pm 12.22 \mathrm{~ms}, t=14.64$ and $p<0.01)$ were found to be lower than in the other group.

\section{CONCLUSION}

There were significantly lower HRR-I values at every recovery stage of the TET. These findings revealed that the autonomic balance is impaired in patients with PEX and that the risk of sudden cardiac death increases.

Keywords: Risk, death, sudden, cardiac, exfoliation syndrome

\section{INTRODUCTION}

The pseudoexfoliative syndrome (PEX) can manifest itself by the accumulation of extracellular fibrillary material in many organs such as the eye and heart. PEX can be easily identified by biomicroscopic examination. White-gray deposition on the pupil edge and in front of the lens is sufficient for diagnosis $(\mathrm{I})$. The substance accumulating in the heart is a risk factor for heart disease and sudden cardiac death. Cardiovascular diseases such as myocardial infarction, arterial hypertension, abdominal aortic aneurysm, heart failure, and coronary artery disease have been shown to be associated with PEX (2). Decreased cardiovascular functions are responsible for most of the mortality and morbidity in PEX patients (3). The incidence of PEX in patients with coronary artery disease and the incidence of atherosclerotic heart disease in patients with PEX have been shown to be higher than in the general population (4). Besides, atherosclerotic heart disease in PEX patients who underwent cataract surgery was again detected at a higher incidence than in the general population (5).

Although HRR-I is a marker that directly reveals the autonomic nervous system functions and is also a reliable predictor of cardiovascular (CV) mortality and morbidity, it is not routinely evaluated in daily clinical practice. HRR-I has been closely associated with morbidity and mortality in $\mathrm{CV}$ diseases $(6,7)$. The autonomic nervous system is one of the most important control mechanisms governing $\mathrm{CV}$ functions; therefore, a deterioration in the autonomic nervous system may lead 
to increased CV morbidity and mortality $(8,9)$. HRR-I is a very important predictor of the effects of vagal activity on the heart, and directly demonstrates the vagal activity $(10,11)$. In the treadmill exercise test (TET), HRR-I indicates the rate of decrease from the peak level in the heart rate of the cooling phase. HRR-I valves can be obtained by extracting the cooling phase heart rates from the HR at the peak level of the TET (I2).

The decrease in parasympathetic system activity and an increase in sympathetic system activity are associated with direct ventricular arrhythmias regardless of the disease or even in healthy individuals. As known, sympathetic activity increases and parasympathetic activity decreases during the exercise. Therefore, most arrhythmias and sudden cardiac deaths can occur immediately after severe exercise (I3). PEX is directly proportional to age (14). SCD occurs at a higher rate than the subgroup over the age of 35 years, and this occurs after severe exercises (15). Although there was no underlying $\mathrm{CV}$ disease in PEX patients, there was a higher incidence of arrhythmias than in the general population. This may indicate that vagal activity may be reduced and sympathetic activity may be increased relatively (16).

Our study aimed to compare the effect of stress testing on HRR-I values in PEX patients and to compare this predictor in the exercise test with a similar control group matched for age and sex.

\section{MATERIALS and METHODS}

\section{Study Design}

Patients were diagnosed with PEX by biomicroscopy, and by the presence of a white-gray extracellular fibrillary material on the pupil edge or in the anterior capsule and were included as the study group. The control group consisted of patients diagnosed as non-PEX in the ophthalmology outpatient clinic.

\section{Study Population}

A total of 253 patients with PEX (199 males, $78.65 \%$ and $54 \mathrm{fe}-$ males, $21.35 \%$ ) were included in the study. The mean age of the study group was $67.37 \pm 12.63$ years. There was no statistically significant difference between the sex ratio and mean age of the study and control groups. The control group consisted of two hundred eighty-eight (186 males, $78.15 \%$ and 42 females, $21.85 \%$ ) patients who were diagnosed as non-PEX by biomicroscopy in the ophthalmology outpatients clinic. The control group had a

\section{Main Points:}

- Pseudoexfoliative syndrome is a disease of old age as it is known.

- With the increasing age, it is expected that autonomic functions deteriorate against the vagal system.

- Advances against the vagal system and in favor of the sympathetic system mean increased cardiovascular mortality.

- Heart rate recovery index is a predictor of parasympathetic activity.

- By using this predictor, high-risk pseudoexfoliative syndrome patients will be selected with a very easy and inexpensive method. mean age of $66.38 \pm 11.93$ years. Exclusion criteria included having atherosclerotic heart disease and those receiving treatment for any reason; having hypertension or diabetes mellitus; deterioration of the liver, kidney, or thyroid functions in routine blood tests; having electrolyte disturbances; previously diagnosed with chronic pulmonary obstructive disease and having bronchodilator medication; having anemia; having a systemic disease that affect the $\mathrm{CV}$ system; having hypertension and antihypertensive medication; having a history of coronary artery disease, having a body mass index (BMI) over $30 \mathrm{~kg} / \mathrm{m}^{2}$, having a positive effort test, which indicates significant atherosclerotic heart illness; smoking; having a diagnosis of atrial fibrillation or having AF rhythm in superficial electrocardiograms; and patients with orthopedic disorders who were unable to perform TET.

\section{Treadmill Exercise Test}

In both groups, after the physical examination, routine blood tests, and routine transthoracic echocardiograms (TTE) and electrocardiograms (ECG) were performed, the TET was performed according to the Bruce Protocol (17). The speed of ECG recordings was at $25 \mathrm{~mm} / \mathrm{sec}$ and the amplitude of th ECG recordings was at $10 \mathrm{~mm} / \mathrm{mV}$. The ECG recordings were taken as basal, peak exercise level, and recovery phases of the TET. HRR-I values were obtained by extracting the HR values of the recovery phases from the peak HR value.

\section{Ethical Approval}

All the procedures performed in this study involving human participants were in accordance with the ethical standards of the Turkey Research Committee and with the 1964 Helsinki declaration and its later amendments or comparable ethical standards. Written permission was obtained from Sincan State Hospital Management Committee (26.08. 2019/22568850-929). Before the study, written informed consent was obtained from all the participants.

\section{Statistical Analysis}

SPSS software (Version 20; IBM SPSS Corp.; Armonk, NY, USA) 20.0 was used for the collection and analysis of the data. Measurements were expressed as mean \pm standard deviation. Analyzes were performed using the t-test. To compare the values of the two different groups, and to compare the different values of the same group, T-Test Calculator for Independent Two Means and T-Test Calculator for Depended Means were used, respectively. The Z test calculator was used to compare the two population proportions. For correlation involving two values of the same group, the Pearson Correlation Coefficient Calculator was used. For all tests with $p<0.05$, the differences were considered statistically significant.

\section{RESULTS}

There were no differences in both groups in terms of socio-demographic findings and baseline clinical findings (Table I)

Considering the BHR, there was no difference in both groups. In the study group, HRs of all the recovery phases were significantly higher than in the control group. Considering the HRR-I valves, there were statistically significant differences between the study and control groups (Table 2). This finding suggests that the autonomic function was impaired much more in the study group than in the control group. 


\begin{tabular}{|c|c|c|c|c|}
\hline Variables & $\begin{array}{l}\text { Study } \\
\text { Group }\end{array}$ & $\begin{array}{l}\text { Control } \\
\text { Group }\end{array}$ & $\begin{array}{c}\text { T or } \\
\text { Z-value }\end{array}$ & $p$ \\
\hline Age, years & $61.72 \pm 4.23$ & $61.86 \pm 3.24$ & 0.41 & 0.68 \\
\hline Male, $\%$ & 71.46 & 71.62 & 0.02 & 0.96 \\
\hline Female, $\%$ & 28.54 & 28.38 & 0.02 & 0.96 \\
\hline $\mathrm{BMI}, \mathrm{kg} / \mathrm{m}^{2}$ & $26.46 \pm 2.69$ & $26.94 \pm 2.44$ & 1.63 & 0.10 \\
\hline Basal SBP, mm Hg & $122.34 \pm 12.74$ & $121.94 \pm 12.53$ & 0.35 & 0.72 \\
\hline Basal DBP, mm Hg & $77.47 \pm 8.52$ & $76.38 \pm 7.84$ & 1.47 & 0.14 \\
\hline Basal HR, beat/mn & $77.83 \pm 6.32$ & $77.32 \pm 5.35$ & 0.96 & 0.33 \\
\hline LV Mass, gram & $175.68 \pm 32.47$ & $177.61 \pm 29.73$ & -0.68 & 0.49 \\
\hline Total Cholesterol, mg/dL & $168.42 \pm 41.57$ & $17 \mid .43 \pm 38.54$ & -0.83 & 0.40 \\
\hline LDL, mg/dL & $102.58 \pm 22.48$ & $105.82 \pm 19.62$ & -1.69 & 0.09 \\
\hline Triglycerides, mg/dL & $165.38 \pm 23.68$ & $167.16 \pm 21.84$ & -0.86 & 0.38 \\
\hline Hemoglobin, gr/dL & $|4.63 \pm 2.2|$ & $14.34 \pm 2.52$ & 1.35 & 0.17 \\
\hline Calcium, mg/dL & $9.4 \mid \pm 1.01$ & $9.33 \pm 0.94$ & 0.90 & 0.36 \\
\hline Sodium, mEq/L & $141.73 \pm 2.64$ & $141.93 \pm 1.99$ & -0.94 & 0.34 \\
\hline Potassium, mEq/L & $4.02 \pm 0.58$ & $4.12 \pm 0.73$ & -1.68 & 0.09 \\
\hline Magnesium, mg/dL & $1.94 \pm 0.26$ & $1.95 \pm 0.33$ & 0.37 & 0.70 \\
\hline
\end{tabular}

\begin{tabular}{|c|c|c|c|c|}
\hline Variables & $\begin{array}{l}\text { Study } \\
\text { Group }\end{array}$ & $\begin{array}{l}\text { Control } \\
\text { Group }\end{array}$ & T-value & $p$ \\
\hline $\mathrm{BHR}, \mathrm{b} / \mathrm{mn}$ & $77.83 \pm 4.23$ & $77.32 \pm 5.35$ & 1.17 & 0.24 \\
\hline $\mathrm{PHR}, \mathrm{b} / \mathrm{mn}$ & $154.25 \pm 6.39$ & $|58.88 \pm 6| \mid$. & 8.19 & $<0.01$ \\
\hline $\begin{array}{l}\text { First-minute recovery } \\
\mathrm{HR}, \mathrm{b} / \mathrm{mn}\end{array}$ & $\mid 33.32 \pm 6.31$ & $126.77 \pm 6.83$ & 11.04 & $<0.01$ \\
\hline $\begin{array}{l}\text { Second-minute recovery } \\
\mathrm{HR}, \mathrm{b} / \mathrm{mn}\end{array}$ & $115.37 \pm 7.13$ & $107.22 \pm 4.98$ & 14.59 & $<0.01$ \\
\hline $\begin{array}{l}\text { Third-minute recovery } \\
\mathrm{HR}, \mathrm{b} / \mathrm{mn}\end{array}$ & $91.48 \pm 7.42$ & $76.68 \pm 9.37$ & 19.46 & $<0.01$ \\
\hline $\begin{array}{l}\text { HRR-I in the first minute, } \\
\mathrm{b} / \mathrm{mn}\end{array}$ & $20.93+/-5.91$ & $32.11+/-5.43$ & -21.78 & $<0.01$ \\
\hline $\begin{array}{l}\text { HRR-l in the second } \\
\text { minute, } \mathrm{b} / \mathrm{mn}\end{array}$ & $38.88+/-6.99$ & $51.65+/-7.12$ & -20.05 & $<0.01$ \\
\hline $\begin{array}{l}\text { HRR-I in the third minute, } \\
\mathrm{b} / \mathrm{mn}\end{array}$ & $62.76+/-7.42$ & $77.21+/-9.22$ & -19.18 & $<0.01$ \\
\hline \multicolumn{5}{|c|}{$\begin{array}{l}\text { Abbr: BHR; Basal Heart Rate, PHR; Peak Heart Rate, HR; Heart Rate, HRR-l; } \\
\text { Heart Rate Recovery Index }\end{array}$} \\
\hline
\end{tabular}

In the study group, the third-minute HR was significantly higher than the basal HR. Besides, in the control group, the third-minute recovery HR was similar to the basal HR. (Table 3). This also suggests that the autonomic functions were impaired much more in the study group than in the control group.

Considering both age and HR, there was a weak, but statistically significant positive correlation in both groups. There were also moderate positive correlations between HRR-I values at each recovery stage of the effort test in both groups (Table 4).

\begin{tabular}{|c|c|c|}
\hline \multicolumn{3}{|c|}{ Study Group ( $n=253)$} \\
\hline Variable I & Variable 2 & p \\
\hline Basal HR & First-minute HR & $<0.01$ \\
\hline Basal HR & Second-minute HR & $<0.01$ \\
\hline Basal HR & Third-minute HR & $<0.01$ \\
\hline \multicolumn{3}{|c|}{ Control Group ( $n=238$ ) } \\
\hline Basal HR & First-minute HR & $<0.01$ \\
\hline Basal HR & Second-minute HR & $<0.01$ \\
\hline Basal HR & Third-minute HR & 0.36 \\
\hline
\end{tabular}

TABLE 4. The correlations of the study and control groups

\begin{tabular}{|c|c|c|c|c|}
\hline $\begin{array}{l}\text { Variable I } \\
\text { The Study }\end{array}$ & \multicolumn{3}{|c|}{ The Study Group } & p \\
\hline Age & $\mathrm{HR}$ & Weak Positive & 0.22 & $<0.01$ \\
\hline Age & HRR-I in Ist minute & Moderate Positive & 0.72 & $<0.01$ \\
\hline Age & HRR-I in 2nd minute & Moderate Positive & 0.69 & $<0.01$ \\
\hline Age & HRR-I in 3rd minute & Moderate Positive & 0.66 & $<0.01$ \\
\hline \multicolumn{5}{|c|}{ The Control Group } \\
\hline Age & HRR-I in Ist minute & Moderate Positive & 0.67 & $<0.01$ \\
\hline Age & HRR-I in 2nd minute & Moderate Positive & 0.57 & $<0.01$ \\
\hline Age & HRR-I in 3rd minute & Moderate Positive & 0.51 & $<0.01$ \\
\hline Age & $H R$ & Weak Positive & 0.28 & $<0.01$ \\
\hline
\end{tabular}

\section{DISCUSSION}

This study had found three interesting findings. The first of these findings was that the third-minute HR value was significantly higher than the basal HR of the study group. In addition, in the control group, there was a similarity between the basal HR and the third-minute recovery HR. The second finding was that there was a statistically significant difference in terms of all the HRR-I values of the recovery phases between both groups. Besides, there were moderate positive correlations between the HRR-I values and the ages of both groups in each recovery stage.

The results of our study showed that the vagal system is less functional in PEX patients than in the non-PEX patients. The delay in HRR-I is directly associated with the decreased vagal activity, and the reduced vagal activity is also characterized by the increased risk of SCD (I8).

SCD generally results in patients with structural heart disease. In particular, it occurs immediately after heavy exercises (19). It is known that sympathetic activity increases with an exercise test; the vagal activity is at the recovery phase after the exercise test. It has been documented that an elevated sympathetic response or a reduced vagal response immediately precedes the onset of atrial and ventricular arrhythmias as well as sudden cardiac death (20). Furthermore, delayed HRR was found to be one of the indirect predictors of decreased vagal activity (2I). In our 
study, we found that there was much more delayed HRR in the study group compared to non-PEX patients.

Many researchers have focused on the association between PEX and CV diseases, searching for underlying events. The first of these was homocysteine. Higher levels of homocysteine were found in patients with PEX than in non-PEX patients $(22,23)$. In addition, vitamin $B \mid 2$, vitamin $B 6$, and folic acid levels were also found to be decreased (24). Although many researchers argued that there were relationships between PEX and other CV diseases, in a recent study, researchers found that only the prevalence of arrhythmias was found to be higher in PEX patients than in non-PEX patients (25).

The underlying mechanisms of arrhythmias in PEX patients have been investigated, and the most commonly considered one was the decreased vagal activity (26). Many indirect methods have been developed to investigate this. One of these is the carotid artery baroreceptor reflex. Compared with non-PEX patients, carotid artery baroreceptor reflex was found to be decreased in PEX patients (27). Some investigators have also found reduced cardio-vagal regulation in PEX patients (28). Most studies on decreased vagal autonomic activity have focused on heart rate recovery. Regardless of the underlying disease, there was a relationship between reduced HRR-I and increased mortality (29).

HRR-I shows the degree of heart rate decrease after exercise (30). At the first-minute recovery phase of the TET, the vagal system plays an important role in decreasing the HR. In addition, at the second and the third-minute recovery phases of the TET, the reducing of the sympathetic system affects the decreasing HR (3I). HRR-I is an independent predictor for all-cause death, regardless of coronary artery disease, left ventricular failure, and low exercise capacity (32). A faster reduction in the first minute is closely associated with a lower risk of mortality (33). It was found that there were relationships between low HRR-I and elevated fasting blood glucose level, elevated triglyceride/ $\mathrm{HDL}$ ratio, duration of diabetes mellitus, the severity of the endothelial dysfunction, and the history of recent myocardial infarction (MI) (34). The ratio of SCD due to $\mathrm{MI}$ is 2 times increased in patients with HRR- $1<25$ beats/minute in the first minute than in those with HRR-I $\geq 25$ beats/minute in the first minute (35).

In conclusion, HRR-I, which has been studied in such a detailed and long-term manner and is an important predictor of all event-related deaths, has never been investigated in PEX patients. We thought that this might be due to the balance disorders in the neurohumoral equilibrium in PEX patients. In our study, HRR-I was found to be lower in the study group than in the control group at each stage, and as a result, it was found that autonomic nervous system balance decreased vagal activity and directly increased sympathetic activity in PEX patients compared to the control group. Therefore, it indicates an increased risk of sudden cardiac death in PEX patients that is higher than in non-PEX patients of the same age and sex.

In our study, the sample size was small. Furthermore, we could not perform 24 hours-Holter monitoring to investigate the ventricular arrhythmias in both groups. In addition, long-term studies should be made to observe the effect of medical therapy on the HRR-I and ventricular arrhythmias induced by the exercise test in patients with PEX. More comprehensive and long-term follow-up studies should be performed to obtain healthier data in PEX patients.

Ethics Committee Approval: Ethics committee approval was received for this study from the ethics committee of Sincan Dr nafiz Korez State Hospital Management (22568850-929/26.08.2019).

Informed Consent: Written informed consent was obtained from all the participants.

Peer-review: Externally peer-reviewed.

Author contributions: Concept - A.C.; Design - A.G.; Supervision - A.C.; Resource - A.C., A.G.; Materials - A.C., A.G.; Data Collection and/or Processing - A.G.; Analysis and/or Interpretation - A.C.; Literature Search - A.C.; Writing - A.C., A.G. ; Critical Reviews - A.C.

Acknowledgements: We thank to Mustafa Hamidullah Turkkani for statistics.

Conflict of Interest: Authors have no conflicts of interest to declare.

Financial Disclosure: The authors declared that this study has received no financial support.

\section{REFERENCES}

I. Wang W, He M, Zhou M, Xiulan Z. Ocular Pseudoexfoliation Syndrome and Vascular Disease: A Systematic Review and Meta-Analysis. PLo S One 2014; 9(3): e92767. [Crossref]

2. Gonen KA, Gonen T, Gumus B. Reply: Pseudoexfoliation syndrome and cardiovascular disease: studies must control for all cardiovascular risk factors. Eye 2013; 27(II): 1329. [Crossref]

3. Mitchell P, Wang JJ, Smith W. Association of pseudoexfoliation syndrome with increased vascular risk. Am J Ophthalmol 1997; 124(5): 685-7. [Crossref]

4. Citirik M, Acaroglu G, Batman C, Yildiran L, Zilelioglu O. A possible link between the pseudoexfoliation syndrome and coronary artery disease. Eye (Lond) 2007; 2I(I): II-5. [Crossref]

5. Andrikopoulos GK, Mela EK, Georgakopoulos CD, Papadopoulos GE, Damelou AN, Alexopoulos DK, et al. Pseudoexfoliation syndrome prevalence in Greek patients with cataract and its association to glaucoma and coronary artery disease. Eye (Lond) 2009; 23(2): 442-7. [Crossref]

6. Vivekananthan DP, Blackstone EH, Pothier CE, Laver MS. Heart rate recovery after exercise is a predictor of mortality, independent of the angiographic severity of the coronary disease. J Am Coll Cardiol 2003; 42(5): 831-8. [Crossref]

7. Morshedi-Meibodi A, Larson MG, Levy D, O'Donnell CJ, Vasan RS. Heart rate recovery after treadmill exercise testing and risk of cardiovascular disease events (The Framingham Heart Study). Am J Cardiol 2002; 90(8): 848-52. [Crossref]

8. Cole CR, Blackstone EH, Pashkow FJ, Snader CE, Laver MS. Heartrate recovery immediately after exercise as a predictor of mortality. N Engl J Med 1999; 34|(I8): 135I-7. [Crossref]

9. Laver MS, Okin PM, Larson MG, Evans JC, Levy D. Impaired heart rate response to graded exercise. Prognostic implications of chronotropic incompetence in the Framingham Heart Study. Circulation 1996; 93(8): 1520-6. [Crossref]

10. Shetler K, Marcus R, Froelicher VF, Vora S, Kalisetti D, Prakash M, et al. Heart rate recovery: validation and methodologic issues. J Am Coll Cardiol 200I; 38(7): 1980-7. [Crossref]

II. Okutucu S, Karakulak UN, Aytemir K, Oto A. Heart rate recovery: a practical clinical indicator of abnormal cardiac autonomic function. Expert Rev Cardiovasc Ther 20II; 9(II): 1417-30. [Crossref]

12. Ardıç I, Kaya MG, Yarlıoglues M, Doğdu O, Büyükoğlan H, Kalay N, et al. Impaired heart rate recovery index in patients with sarcoidosis. Chest 20II; I39(I): 60-8. [Crossref] 
13. San Antonio R, Guasch E, Tolosana JM, Lluís M. Determining the best approach to reduce the impact of exercise-induced atrial fibrillation: prevention, screening, or symptom-based treatment? Expert Rev Cardiovasc Ther 2018; 17(1): 19-29. [Crossref]

14. Kling F, Colin J. Potential association of pseudoexfoliation syndrome (PEX) with age-related macular degeneration (ARMD). J Fr Ophthalmol 200I; 24(I): 7-I2.

15. Sumeet S. Chugh, Joseph B. Weiss. Sudden Cardiac Death in the Older Athlete. J Am Coll Cardiol 2015; 65(5): 493-502. [Crossref]

16. Brajkovic J, Surac IK, Ercegovic A, Miletić-Jurić A, Sušić N, Burić Z. Ocular Pseudoexfoliation syndrome and internal systemic diseases. Acta Clin Croat 2007; 46(suppl I): 57-61.

17. Bruce RA. Exercise testing of patients with coronary heart disease. Principles and normal standards for evaluation. Ann Clin Res 1971; 3(6): 323-32.

18. Jae SY, Bunsawat K, Kunutsor SK, Eun Sun Yoon, Hyun Jeong Kim, Mira Kang, et al. Relation of Exercise Heart Rate Recovery to Predict Cardiometabolic Syndrome in Men. Am J Cardiol 2018: 123(4): 582-7. [Crossref]

19. Campuzano O, Sanchez-Molero O, Fernandez A, Mademont-Soler I, Coll M, Perez-Serra A, et al. Sudden Arrhythmic Death During Exercise: A Post-Mortem Genetic Analysis. Sports Med 2017; 47(I0): 2I0I-15. [Crossref]

20. Zhou S, Jung BC, Tan AY, Vinh QT, Ghassan G, Seong-WH, et al. Spontaneous stellate ganglion nerve activity and ventricular arrhythmia in a canine model of sudden death. Heart Rhythm 2008; 5(I): |3| -9. [Crossref]

21. Nederend I, Schutte NM, Bartels M, Arend DJ Ten Harkel, Eco JC de Geus. Heritability of heart rate recovery and vagal rebound after exercise. Eur J Appl Physiol 2016; II6(II-12): 2167-76. [Crossref]

22. Bleich S, Roedl J, Von Ahsen N, Ursula S-S, Udo R, Georg B, et al. Elevated homocysteine levels in aqueous humor of patients with pseudoexfoliation glaucoma. Am J Ophthalmol 2004; I38(I): 162-4. [Crossref]

23. Roedl JB, Bleich S, Reulbach U, Robert R, Johannes K, Friedrich EK, et al. Homocysteine in tear fluid of patients with pseudoexfoliation glaucoma. J Glaucoma 2007; 16(2): 234-9. [Crossref]

24. Roedl JB, Bleich S, Reulbach U, Rejdak R, Naumann GOH, Kruse FE, et al. Vitamin deficiency and hyperhomocysteinemia in pseudoexfoliation glaucoma. J Neural Transm 2007; II4(5): 57I-5. [Crossref]
25. Ercegoviae A, Brajkoviae J, Surace IK, Marijana BH. Prevalence, distribution, and types of corneal astigmatism in cataract surgery patients in Sibenik Country. Acta Clin Croat 2012; 5I(2): 275-8.

26. Hollo G, Lakatos P, Farkas K. Cold pressor test and plasma endothelin-I concentration in primary open-angle and capsular glaucoma. J Glaucoma 1998; 7(2): 105-I0. [Crossref]

27. Visontai Z, Merisch B, Kollai M, Gábor H. Increase in carotid artery stiffness and decrease of baroreflex sensitivity in exfoliation syndrome and glaucoma. Br J Ophthalmol 2006; 90(5): 563-7. [Crossref]

28. Visontai Z, Horváth T, Kollai M, Gábor H. Decreased cardiovagal regulation in exfoliation syndrome. J Glaucoma 2008; 17(2): 133-8. [Crossref]

29. Peçanha T, Silva-Júnior ND, Forjaz CL. Heart rate recovery: autonomic determinants, methods of assessment and association with mortality and cardiovascular diseases. Clin Physiol Funct Imaging 2014; 34(5): 327-39. [Crossref]

30. Laver M, Froelicher ES, Williams M, Kligfield P, American Heart Association Council on Clinical Cardiology SoECR, Prevention. Exercise testing in asymptomatic adults: a statement for professionals from the American Heart Association Council on Clinical Cardiology, Subcommittee on Exercise, Cardiac Rehabilitation, and Prevention. Circulation 2005; II2(5): 77I-6. [Crossref]

31. Sears CE, Choate JK, Paterson DJ. Inhibition of nitric oxide synthase slows heart rate recovery from cholinergic activation. J Appl Physiol (1985) 1998; 84(5): 1596-603. [Crossref]

32. Vivekananthan DP, Blackstone EH, Pothier CE, Laver MS. Heart rate recovery after exercise is a predictor of mortality, independent of the angiographic severity of the coronary disease. J Am Coll Cardiol 2003; 42(5): 831-8. [Crossref]

33. Morshedi-Meibodi A, Larson MG, Levy D, O'Donnell CJ, Vasan RS Heart rate recovery after treadmill exercise testing and risk of cardiovascular disease events (The Framingham Heart Study) Am J Cardiol 2002; 90(8): 848-52. [Crossref]

34. Panzer C, Laver MS, Brieke A, Blackstone E, Hoogwerf B. Association of fasting plasma glucose with heart rate recovery in healthy adults: a population-based study. Diabetes 2002; 5I(3): 803-7. [Crossref]

35. Jouven X, Empana JP, Schwartz PJ, Desnos M, Courbon D, Ducimetiere P. Heart-rate profile during exercise as a predictor of sudden death. N Engl J Med 2005; 352(19): 1951-8. [Crossref] 